\title{
The Research on Innovative Development Path of New Retail Business Model Based on Customer Experience
}

\author{
Lu Ying ${ }^{1}$, Zhao Yan ${ }^{2}$, Fan Zhipeng ${ }^{1}$, Liu Yan ${ }^{1}$ \\ ${ }^{1}$ School of Computer and Information Engineering, Harbin University of Commerce, \\ Harbin 150028, China \\ ${ }^{2}$ Student Career Guidance Center, Harbin University of Commerce, Harbin 150028, \\ China \\ 0451_ly@sina.com
}

\begin{abstract}
In the 21 century, the competition between enterprises is no longer limited to the competition of products, technologies and services, but the competition of business models. The reform brought by the innovation of business models plays a vital role in the long-term development of enterprises. The New Retail business model integrates new technologies such as Artificial Intelligence, Big Data and Could Computing from the perspective of improving costumer experience. While inheriting the advantages of traditional business model, the New Retail business model also developed and innovated the traditional business model. After clarifying the understanding of these problems, the paper points out the theoretical for the business model reform of new retail enterprises, and put forward some target suggestions.
\end{abstract}

Keywords: New Retail, Business Model, Customer Experience

\section{Introduction}

With the change of life style, consumers' demands have been more diversified, and shopping has changed from bling buying to rational and selective buying. With the infinite increase of scene and entrance, customers become the real center of retail. When customers experience the information of goods or understand the purchase situation, they will have the purchase behavior, and they are more willing to pay for the service and experience. The New Retail business model can well meet the needs of consumers, break the boundary of traditional retail, integrate online and offline services through modern information technology, and reconstruct the three key elements of people, goods and market. Among them, "people" refers to customers, and the concept of customers' demand for goods is not just a concept of goods. Goods, services and experiences constitute a complete concept of goods in line with the changing concept of current consumer demand.

\section{New Retail Business Mode}

\subsection{Connotation of the New Retail Business Model}

Article history:

Received (December 29, 2018), Review Result (February 6, 2019), Accepted (August 22, 2019) 
New retail is a new model of retail that enterprises rely on the Internet, through Big Data, Artificial Intelligence, and other advance technology, upgrades the production, circulation and sales process of products, breaks the unilateral development of online and offline, and further integrates online and offline services to fully integrate their advantages. Ali Research Institute released "a research report on New Retail", which made a comprehensive and in-depth analysis of New Retail and pointed out that "New Retail is a data-driven pan-retail pattern centering on consumer experience". Later, JD also proposed that the era of "New Retail" will bring us into the era of intelligent commerce, which is a new revolution beyond the Internet.

\subsection{Theoretical Support for the New Retail}

The theoretical support of the New Retail theory is the "The Wheel of New Retail" theory, which is developed on the basis of the "The Wheel of Retail" theory. The theory of "The Wheel of New Retail" explains the changing process and rules of retail formats from the perspective of industry, and its theoretical framework is divided into four elements, including "technology edge", "equivalent thread", "retail price", and "retail service level", as shown in figure 1.

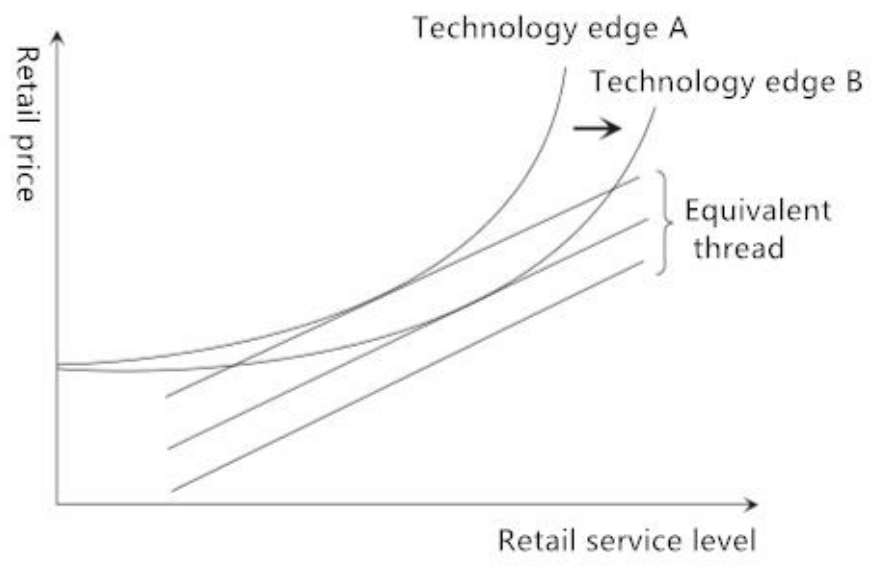

Figure 1. The theoretical explanation of "The wheel of New Retail"

Of these, "technology edge" represents the lowest horizontal line reached by retail price under a fixed service level. Affected by the law of diminishing returns, technology edge extends to the upper right. The combination above the technology edge is high price and high service; the combination below technology edge is low price and low service. When various technical levels are constant, the closer the price and service provided by the retail enterprise are to the technology edge, the more competitive the enterprise has in the industry. In addition, the competition among retail enterprises is usually manifested in the improvement of service level or the reduction of price and reflected in the movement along the technology edge. From the analysis of economic theory, when technological innovation drives the technology edge, there will always be an equivalent thread are tangent to it. At this point, the utility of consumers has not changed significantly, but they can enjoy a high service at a certain price level or a low price under certain services. At this point, consumers get tangible benefits, and retailers on the left side of the technology edge gradually lose market share and competitiveness. The enterprises that near new technology edge obtain excess profits, demonstrative effect and 
diffusion effect at the same time. It promoted other enterprises to follow suit promote technology edge moving again, make the excess profit of advantage enterprise disappear and then again enter into the fierce competition phase, prompted a new round of technological change. Until now, the technology edge moves to the bottom right and the new retail formats emerge.

\subsection{The Relationship between New Retail and Traditional Retail}

"New Retail" is developed on the basis of traditional retail. It is a new thing emerging in the Internet era that aims at the plight and disadvantages of traditional retail and seeks for a new way out. Traditional retail pays more attention to the enterprises' own efficiency and benefit acquisition, while New Retail pays more attention to user experience, value creation and long-term cooperation. Traditional retail stores pay more attention to logistics distribution in traditional ways, unable to meet more requirements of customers. "New Retail" pays more attention to the application of Cloud Computing, Big Data, The Internet, Artificial Intelligence and other high-technology, and makes the data management of products, logistics, customers and other data. It emphasizes the combination of information flow and logistics, it pursues Omni-channel and borderless cooperation and mutual benefit and win-win results. Specifically, the "New Retail", in fact, is to promote the development of traditional physical retail industry with the development of new internet-based retail formats, integrate new Internet technologies into traditional physical retail industry, so as to revitalize the traditional entity retail industry, and make the Internet retail industry obtain new growth points. The development connotation of the new retail business model is shown in figure 2 .

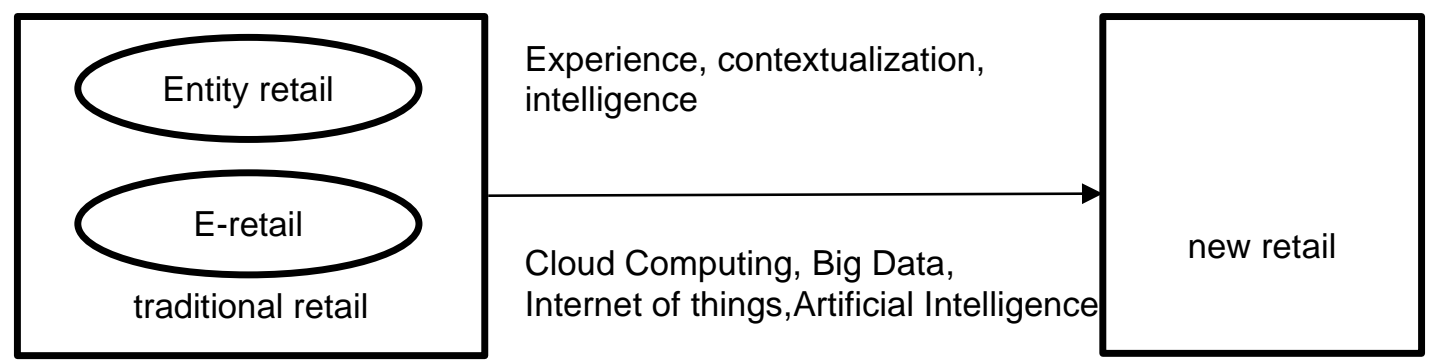

Figure 2. The relationship between new retail and traditional retail

\section{Building a New Retail Business Model Centered on Customer experience}

The main feature of the New Retail business model is to emphasize the scene innovation and consumer experience. That is, taking customer experience as the core, using new technology to build a new shopping scene, so that customers can feel the value of products or services in the scene, and then improve customer satisfaction and loyalty.

\subsection{Connotation of Customer Experience}

In recent years, scholars pay more attention to the research of customer experience. Carbon, Lewis P and Haeckel, Stephan H (1994) believe that customer experience refers to the accumulated perception of customers when they learn, own, use and even discard a product or service [1]. Christopher Meryer, Andre Schwager (2007) believe that customer experience is an individual response of customers from the process of direct or indirect contact with the 
enterprise, in which contact includes direct behaviors caused by customers, such as purchase process, use process and service process, and indirect contact refers to a business representative, service or contact with the enterprise [2]. Zhang Yimei (2004) proposed that customer experience is the individualized feeling of customers to certain stimuli. After producing Ecommerce shopping mode, the concept and content of customer experience are different from the traditional physical shopping environment [3]. Cao Yuanyuan and other scholars (2014) think that the experience of customers in the E-commerce environment is the psychological feeling generated in the process of contacting with enterprises during online shopping [4].

\subsection{Dimensions of customer experience}

Consumer experience is three-dimensional and multi-dimensional. As the New Retail is the integration of offline and online services, offline experience and online experience have their own characteristics, while they are interrelated and inseparable in the new retail environment. This studies from the dimensions of offline experience, online experience.

Scholars began to study the dimension of offline experience relatively early, and the content is also very rich. Schmintt (1999) divided the dimensions of customer experience into sensory experience, emotional experience, thinking experience, action experience and relationship experience [5]. Many scholars carry out further research and practice on this basis. From the perspective of cognitive theory, Josko Brakus (2001) proposed that customer experience theory includes five types of experience: feeling, emotion, intelligence, body and social interaction, which has two independent response levels---the first and second levels [6]. Zhou Zhaoqing (2004) combined with Schmitt's point of view and Maslow's demand level theory, divided the experience into three dimensions, namely: entertainment experience, emotional experience and cultural experience [7]. Guo Hongli and Yuan Daowei (2005) believe that customer experience can be reflected in respect, trust, convenience, commitment, control, choice, knowledge, cognition, benefit, identity and glory [8].

Under the network environment, creating a comfortable online shopping environment for customers has a lot of positive effects on enterprises. Jeff Bezos, founder of Amazon, believes that creating a comfortable online shopping experience is the key competitive advantage of Internet enterprises. In the Internet shopping environment, the dimension of customer experience is different from offline customer experience. Nysveen and other scholars believe that the dimension of online experience has three aspects: customer perception of website usefulness, customer perception of website usability, and customer interaction with interactive applications on the website.

\subsection{Elements of New Retail Business Model}

The concept of business model mainly reveals the essential content of business model, and the elements of business model are the concrete generalization of the essential content of business model, reflecting the core logic of business model. The components of the New Retail business model include the following aspects:

\subsubsection{Value proposition:}

The basis of business model innovation is value proposition innovation. In the era of increasingly personalized and diversified customer needs, the New Retail model focuses on customers and defines customers that need to be focused on and serviced. On this basis, it determines differentiated and accurate value propositions, improves the loyalty of target 
customers, and improves the value potential of target customers, so as to realize the value of the enterprise itself.

\subsubsection{Operating Efficiency :}

The New Retail reduces the communication cost of the transaction; improves the efficiency of the transaction, which cannot be limited by the time and space scenarios, and improves the transaction frequency of the commodity; the openness and transparency of the commodity and price information improves the selection efficiency of consumers; the credit guarantee of payment makes the sales receipt faster and more convenient, and the capital can enter the next production and consumption cycle faster; centralized distribution Improve the efficiency of logistics distribution.

\subsubsection{Profit Model:}

Under the background of the New Retail model, the way of profit is not limited to the single aspect in the past. In the process of integration, the entity retail enterprises and E-commerce should actively seek more profit models based on their own advantages. In the context of New Retail, we can build a diversified marketing service platform, "Retail + Experience" consumption mode, and use high cost performance, wide coverage, focus on customer service, cultural publicity and other promotion to enhance the stickiness of relevant corporate brands and customers. Diversified services can not only obtain new customers, but also fully retain the original old customers in order to make consumers become loyal users.

\subsubsection{Core competence:}

The rise of New Retail is supported by business logic and forms its unique core competitiveness. New retail is cross-border, even boundless. The connection between consumers and retailers is boundless. A member account can establish all connections. The whole process of sales can be perfectly realized no matter whether it is physical shopping or virtual channel. This not only saves the time of channel selection, but also enables online and offline channels to fully interact and share resources.

\section{Innovative Development Path of New Retail Business Model}

\subsection{Deep Understanding of Customer Needs to Meet Customer Shopping Experience}

In modern society, great changes have taken place in the concept of customer consumption. Enterprises must design the shopping experience from the perspective of customer shopping, that is, the display of goods before purchase, motivation stimulation, product introduction, scene design, pleasant feeling, convenience, after-sale service after purchase, product tracking feedback, relationship maintenance, etc. Using the massive, multi-dimensional and threedimensional information collected by modern information technology to quickly screen out valuable information for the company, accurately judge and analyze the customer behavior mode and customer value, classify the customer data from multiple dimensions, and assign different data labels. Then through the design of precision marketing model, we can help enterprises push "correct content" in the "right channel" at the "right time" for the "right customers" in the "right way of promotion" to meet the real needs of customers. 


\subsection{All Channel Resource Integration, Open O2O Mode}

In the New Retail era, physical retail does not disappear. From the perspective of the development trend of commercial retail, the vitality of physical stores is still strong, but the function of physical retail has changed, and the business mode and format have also changed. In the future, more and more physical retail outlets will become the center of life, the terminal of life or the gathering place of life. When consumers come to these physical stores, they can experience consumption, enjoy their life, enhance feelings, and get more experience value and emotional value at the same time of shopping. Online shopping is rich in categories and convenient. The integration of the New Retail industry includes the integration of upstream and downstream relationships, and the use of the platform to build an ecological model of information transfer for businesses. Retail enterprises need to transfer customer demand information to upstream suppliers in time to promote on-demand production of suppliers. In addition, they need to convey the high-quality production concept of upstream suppliers to downstream consumers in order to achieve value-added benefits.

\subsection{Relying on Science and Technology to Improve Core Competitiveness}

In the era of Internet, enterprises still need to rely on science and technology to improve their core competitiveness. To strengthen the use of Internet technology and investment in new technology is the fundamental guarantee for New Retail enterprises to have sustainable power. Through the application of big data, cloud computing, Internet of things, artificial intelligence and other advanced technologies, analyze the behavior of consumers, and deeply tap the needs of consumers. New Retail enterprises sell not only simple goods, but also various innovative technologies. Therefore, the innovative New Retail business model also needs to pay attention to the $R \& D$ and use of new technology in order to make business model innovation have strong technical support.

\subsection{Optimize Supply Chain and Develop Logistics Distribution System}

Establish a predictable supply chain coordination and optimization system to meet the logistics needs of multiple batches and fewer batches. Implement open supplier strategy and provide data, logistics and other services to suppliers. In addition, retail enterprises cooperate with upstream, midstream and downstream enterprises to realize information sharing, so as to quickly adjust the resources of each link of the supply chain to meet the personalized retail demand in the market. Vigorously develop logistics and distribution, shorten the time difference between customers' online orders and arrival, and reduce the time risk perception of consumers' online shopping. Logistics is the key link of online and offline optimization and integration of New Retail, and it is also the last link of retailers' online channel and customers' zero distance contact.

\section{Conclusion}

In the New Retail era, the change of people's consumption habits requires that retail enterprises must innovate their own business models. Retail enterprises need to establish new business models to break the gap between physical retail enterprises and E-commerce enterprises, re -establish the relationship between physical retail enterprises and E-commerce enterprises, and promote the better and faster development of traditional retail enterprises. Based on the connotation and dimension of customer experience, this paper analyzes the connotation, development motivation and elements of the New Retail business model of the 
retail industry, puts forward the best choice for the development of the New Retail business model, summarizes the development path, which has certain theoretical significance for the development of the New Retail business model in China.

\section{Acknowledgements}

Supported by the 2018 Heilongjiang philosophy and social sciences research planning project (approval No. 18GLE464).

\section{References}

[1] Carbone, Lewis P, Haeckel, Stephan H. "Engineering Customer Experiences". Marketing Management.3 (1994)

[2] Meyer C, Schwager A. "Understanding customer experience". Harvard Business Review, Vol.85, No.2, pp.116-142 (2007) DOI: 10.1177/1059601106286882

[3] Zhang Yimei. "Experience marketing, a new strategy to win competitive advantage in the new era". Chinese collective economy 1 (2004)

[4] Cao Garden, Zhang Jianshe, and Pan Yonggang. "Research on the evaluation index system of e-commerce customer experience" Statistics and Decision 03 (2014)

[5] Schmintt,B.H., "Experiential Marketing: How to Get Customers to SENSE,FEEL,THINK,ACT, RELATE to Your Company and Brands", New York:Simon \&Schuster Inc (1999)

[6] Josko Brakus. "A theory of consumer experiences". Columbia Universtiy,(2001)

[7] Zhou Zhaoqing. "Experience marketing”. Guangxi ethnic Publishing House (2004)

[8] Guo Hongli, Yuan Dawei. "The customer experience management - experience the new rules of customer management in the economic times". Tsinghua University Press (2010) 
The Research on Innovative Development Path of New Retail Business Model Based on Customer Experience 